\title{
ARTIGO
}

COI https://doi.org/10.22481/praxisedu.v15i36.5892

\section{OCUPAÇÕES DAS ESCOLAS PÚBLICAS NO RS: SOCIALIZAÇÃO POLÍTICA, REPRESENTAÇÃO E LIDERANÇA ENTRE SECUNDARISTAS}

OCCUPATIONS OF PUBLIC SCHOOLS IN RS: POLITICAL SOCIALIZATION, REPRESENTATION AND LEADERSHIP AMONG SECONDARY SCHOOL STUDENTS

\author{
OCUPACIONES DE LAS ESCUELAS PÚBLICAS EN EL RS: \\ SOCIALIZACIÓN POLÍTICA, REPRESENTACIÓN Y LIDERAZGO ENTRE \\ SECUNDARISTAS
}

Ricardo Gonçalves Severo

Universidade Federal do Rio Grande - Brasil

Sérgio Botton Barcellos

Universidade Federal do Rio Grande - Brasil

Mário Augusto Correia San Segundo

Instituto de Educação, Ciência e Tecnologia do Rio Grande do Sul - Brasil

\begin{abstract}
Resumo: O artigo tem como questão central analisar como se constitui a percepção do papel das lideranças e representação por parte dos (as) estudantes secundaristas que realizaram ocupações nas escolas estaduais durante o ano de 2016 no Rio Grande do Sul/Brasil. A pesquisa qualitativa foi realizada em 2016 em duas cidades (Pelotas e Rio Grande), com posterior entrevista com informante de ocupação em escola na cidade de Porto Alegre, no ano de 2017. Como procedimentos de pesquisa foram realizados dez grupos de discussão e aplicação de questionário semiestruturado a sessenta e cinco estudantes com idades entre doze e dezenove anos e uma entrevista semiestruturada com informante de ocupação em Porto Alegre. Percebeu-se duas visões centrais sobre liderança, sendo a primeira do grupo dos que não reconhecem a existência de liderança e tem uma visão considerada negativa sobre esta categoria, relacionando-a ao formalismo, autoritarismo e ausência ou distância, apontando como modelo ideal formas horizontais de organização. O segundo grupo identifica lideranças e compreendem-nas como aqueles que realizavam maior parte das tarefas e que estão mais imersos no cotidiano das ocupações. O que é comum entre os grupos é que é considerada legítima a participação em termos de intensidade e envolvimento com a pauta.
\end{abstract}

Palavras chave: juventude, ocupação; liderança; socialização política.

Abstract: The article has as central question to analyze how is constituted the perception of the role of the leaderships and representation by the high school students who carried out occupations in the state schools during the year of 2016 in Rio Grande do Sul / Brazil. Qualitative research was carried out in 
2016 in two cities (Pelotas and Rio Grande) with a subsequent interview with an occupant informant at a school in the city of Porto Alegre in 2017. Ten research groups were used as discussion procedures and semi-structured questionnaire to sixty-five students between the ages of twelve and nineteen and a semi-structured interview with occupational informant in Porto Alegre. It was perceived two central visions about leadership, being the first of the group of those who do not recognize the existence of leadership and has a view considered negative about this category, relating it to formalism, authoritarianism and absence or distance, pointing to horizontal models as ideal model of organization. The second group identifies leaderships and understands them as those who perform most of the tasks and who are more immersed in the daily life of the occupations. What is common among the groups is that participation in terms of intensity and involvement with the agenda is considered legitimate.

Keywords: youth; occupation; leadership; political socialization.

Resumen: El artículo tiene como cuestión central analizar cómo se constituye la percepción de los liderazgos y representación por parte de los (las) estudiantes secundarios que realizaron ocupaciones en las escuelas provinciales durante el año 2016 en Rio Grande do Sul / Brazil. La investigación cualitativa fue realizada en 2016 en dos municipios (Pelotas y Rio Grande), con posterior entrevista con informante de ocupación en escuela en el municipio de Porto Alegre, en el año 2017. Como procedimientos de investigación se realizaron diez grupos de discusión y aplicación de: cuestionario semiestructurado a sesenta y cinco estudiantes con edades entre doce y diecinueve años y una entrevista semiestructurada con informante de ocupación en Porto Alegre. Se percibió dos visiones centrales sobre liderazgo, siendo la primera del grupo de los que no reconocen la existencia de liderazgo y tiene una visión considerada negativa sobre esta categoría, relacionándola al formalismo, autoritarismo y ausencia o distancia, apuntando como modelo ideal formas horizontales de organización. El segundo grupo identifica a líderes y las entienden como aquellos que realizaban mayor parte de las tareas y que están más inmersas en el cotidiano de las ocupaciones en las escuelas. Lo que es común entre los grupos es que se considera legítima la participación en términos de intensidad e implicación con la pauta.

Palabras clave: juventud, ocupación; liderazgo; socialización política.

\section{Introdução}

Em um período histórico recente, desde as lutas por uma educação pública e de qualidade nos anos 80 realizadas pelas organizações e movimentos pela educação pública contra as reformas educacionais do governo federal nos anos noventa, observa-se a construção de um conjunto de pautas e formas de mobilização reivindicando melhorias na educação pública brasileira. Ao mesmo tempo observamos o acontecimento de uma série de reformas estruturais no aparelho do Estado no Brasil que foram articuladas às políticas governamentais voltadas para "modernizar" o país e de acordo com a ideologia do Estado mínimo, com a privatização de empresas públicas, a abertura da economia ao mercado externo e a desregulamentação das relações de trabalho.

Diante desse contexto, no âmbito da América Latina, em um período histórico recente, o processo de mobilização estudantil no Chile a partir de 2006 chama a atenção. Naquele ano, 
quando Michelle Bachelet foi recém-empossada, ocorreu uma mobilização estudantil com 10 mil estudantes que começou como um protesto pela gratuidade do passe escolar e a diminuição do valor da inscrição na Prova de Seleção Universitária (PSU). Em 30 de maio de 2006 teve início a Revolta dos Pinguins, em alusão às cores dos uniformes utilizados pelos (as) estudantes. A mobilização iniciada em anos anteriores passou a constituir como uma grande mobilização, protagonizada por estudantes secundaristas que entraram em greve, tomaram as escolas, organizaram assembleias e saíram em passeatas, recebendo apoio de outros setores da sociedade civil, com a participação de até um milhão de pessoas (DE LA CUADRA, 2008). O acúmulo organizativo dessas manifestações reverberou pelo mundo, sendo publicizados em materiais, como, por exemplo, o manual "Como ocupar uma escola", divulgando a tática de ocupações de escolas pelo mundo (DE LA CUADRA, 2008; JANUÁRIO et al., 2016).

No estado de São Paulo (SP) no Brasil em 2015, no governo Alckmin (PSDB), começa a discussão sobre a proposta do estado deixar de ser mantenedor direto dos serviços e passar a incorporar a gestão privada em seus chamados "serviços públicos não estatais", como as escolas. Essa medida implicava no fechamento de algumas escolas e na redução de salas de aula (CAMPOS; MEDEIROS; RIBEIRO, 2016).

Esse conjunto de medidas sem a consulta dos (as) estudantes secundaristas iniciou um processo de críticas nas redes sociais (Facebook, Twiiter e Wattsapp) devido o modo como foram informados sobre a "reorganização das escolas", somente pela imprensa, e quanto ao conteúdo das propostas. Antes das primeiras ocupações ocorrerem nas escolas estaduais de São Paulo, anteriormente nas redes sociais havia uma série de posts, hashtags, abaixoassinados e muitos comentários, inclusive nas publicações da Secretaria da Educação em protesto as medidas anunciadas ${ }^{1}$ (JANUÁRIO et al., 2016).

Em novembro de 2015, a Escola Estadual Diadema, em São Paulo, foi ocupada por estudantes, e logo após a Escola Fernão Dias Paes também ocorreu. A partir de então, essas ações se difundiram e mais de 200 escolas foram ocupadas no mês seguinte. Os estudantes também realizaram uma série de ações em consonância com as ocupações como trancamentos de rua, marchas e ações de agitação e propaganda, sempre com um grande suporte e apoio nas redes sociais. Em dezembro de 2015, o governo estadual anunciou a suspensão do processo de

\footnotetext{
${ }^{1}$ A reorganização necessária não estava na transferência dos (as) jovens de uma escola para outra, mas na resolução de problemas estruturais do sistema, como as salas superlotadas, a insuficiência de recursos materiais e humanos, o precário regime de contratação dos professores, a falta de bibliotecas, de laboratórios e de computadores (JANUÁRIO et al., 2016).
} 
fechamento de escolas, o que correspondeu à queda do Secretário de Educação, na época e a respectiva desocupação nas semanas seguintes.

As ocupações de escolas em São Paulo tiveram uma grande repercussão pelo Brasil e após esses atos, no início de 2016 os estudantes secundaristas de Goiás ocuparam as escolas estaduais em protesto contra a militarização (27 escolas geridas pela Polícia Militar) e a terceirização da gestão das escolas públicas pelo governador Marconi Perillo via Decreto n. 8.469 que determinou a transferência da gestão de 30\% das escolas estaduais para as chamadas Organizações Sociais (OS). A seleção das OSs significava transferir a gestão de escolas públicas para uma organização social, ou seja, empresários contratados para administrar o sistema educacional do estado. Antes de desocuparem as escolas, no final de março de 2016, os estudantes conseguiram ao menos politizar a pauta da militarização e da privatização do ensino estatal, bem como adiar a transferência da gestão para as OS.

Ainda em 2016, os (as) estudantes secundaristas do Paraná (PR) em protestos que reivindicavam que o governo retirasse a proposta de reforma do ensino médio, feita pelo governo Temer por meio de medida provisória na qual atualmente já é uma lei sancionada. Eles (as) também protestavam contra a PEC 241, aprovada na Câmara dos Deputados, que impõe limites aos gastos públicos. Das 2.147 escolas da rede estadual de ensino do Paraná, 590 foram ocupadas por estudantes, de acordo com a Secretaria Estadual de Educação (Seed), mas o movimento Ocupa Paraná afirmava que 850 escolas foram ocupadas.

No estado do Rio Grande do Sul (RS), no dia 11 de maio de 2016, a ocupação da Escola Estadual Emílio Massot realizada pelos seus estudantes, em Porto Alegre, iniciou uma onda de ocupações e de mobilizações por parte dos estudantes secundaristas no RS. De maio a julho do ano passado foram mais de 150 escolas ocupadas por estudantes em todas as regiões do estado. Dentre as diferentes regiões do RS, na metade sul do estado nos municípios de Pelotas e Rio Grande, a partir do dia 13 de maio registram-se cerca de 20 ocupações de escolas estaduais. As ocupações foram tendo vulto concomitantemente com a greve dos professores da rede estadual e também contaram com apoio do Sindicato dos Professores do Rio Grande do Sul - CPERS.

Nas redes sociais o movimento passou a postar a hash tag \#OcupaRS e além da reivindicação pela melhora da educação frente às políticas do Estado, houveram as disputas por apoio e solidariedade por parte das diversas entidades e comunidade de pais/mães/responsáveis e estudantes. No caso das escolas gaúchas, as pautas variavam de acordo com o município e a escola. Entretanto, as condições insalubres de trabalho dos professores e a falta de manutenção das escolas com o agravamento do parcelamento dos 
salários que vem sendo praticado desde 2015 até os dias de hoje, pelo governo Sartori (PMDB) foram questões gerais que nortearam as mobilizações. Além dessas pautas mais cotidianas e relativas à infraestrutura constava comumente nas pautas a questão dos Projetos de Leis 44/2015 (privatização do ensino) e 190/2016 (Escola Sem Partido)².

No caso específico das escolas ocupadas nos municípios de Pelotas e Rio Grande (que serão abordadas nesse estudo) as ocupações iniciaram a partir das ocupações no RS, mas foram deliberadas em assembleias e reuniões. Percebeu-se que para a mobilização do conjunto dos (as) estudantes foi intenso o uso das redes sociais via Whatsapp e Facebook para. Além disso, percebemos nos relatos dos grupos de estudantes que a motivação inicial também foi relativa ao sentimento de solidariedade com os (as) professores (as).

Diante dessas mobilizações, na busca de reflexão sobre estes processos o presente artigo traz como questão central de pesquisa: Como ocorreu o processo de socialização política para a formação de lideranças e representação por parte dos estudantes secundaristas nas ocupações das escolas? O objetivo é problematizar a percepção dos (as) estudantes secundaristas sobre a categoria liderança e como a mesma foi construída nas ocupações das escolas públicas de Pelotas e Rio Grande (RS) nas dimensões organizativa e política.

A difusão destas mobilizações dos (as) estudantes no Brasil passa a ser tema de análise de uma série de pesquisas acadêmicas, enfocando, por exemplo, os aspectos organizativos e objetivos (CATINI; MELLO, 2016), as ocupações como contestação ao modelo de educação e novas formas de ação política (CATTANI, 2017; CORTI; CORROCHANO; SILVA, 2016; ROSÁRIO; SILVA; SILVA, 2016), e também a reflexão sobre o conceito de juventude e a relação que têm com o exercício da política (SILVA; SILVA, 2017; SALLAS, 2017). Sob essa perspectiva, a noção de liderança e sociabilidade política terá como lente analítica Bourdieu (2004) e Dubar (2006) com aporte teórico auxiliar em Tomizaki, Carvalho Silva (2016), Palacios e Valadares (2016), dentre outros atores. A partir disso, buscaremos compreender o que os grupos de referência compreendem ser liderança e, conforme os relatos, quais são as razões da aceitação e rejeição da existência desta categoria a partir da participação nas ocupações. Desta forma o entendimento do que é ou pode ser a liderança, assim como a rejeição desta compreensão, auxilia a entender além do papel da construção de uma divisão que surgiu nas ocupações, os processos organizativos políticos contemporâneos e as dinâmicas de construção política entre jovens.

\footnotetext{
${ }^{2}$ O primeiro projeto é a versão local do projeto "Escola Sem Partido" que busca impedir o debate político na escola, local que, neste período de vida, se torna espaço essencial e mais relevante de socialização. O segundo busca autorizar o credenciamento de Organizações Sociais (OSs), para que assumam a administração de estruturas estatais, entre outras, do ensino público.
} 
A pesquisa foi realizada em 2016 em dez escolas 3 nos municípios de Pelotas e Rio Grande no estado do Rio Grande do Sul (RS). Estes municípios ficam posicionados geograficamente no sul do estado, e são de importância estratégica, pois compõem um pólo educacional e econômico considerável, com a presença de indústrias, forte comércio e do Superporto de Rio Grande. Em termos populacionais, são duas cidades consideradas como médias no estado e formam uma pequena região metropolitana no extremo sul do país.

A metodologia dessa pesquisa é qualitativa. Buscamos o entendimento da construção das ocupações pelo protagonismo de alguns estudantes que tomaram a frente das mobilizações, apoiando-se na rede social em formação e que em determinadas situações foram ou compreendidos enquanto liderança ou rejeitavam esta caracterização. Os procedimentos de pesquisa foram entrevistas em profundidade ${ }^{4}$ por saturação de amostra teórica (FONTANELLA, 2011). As entrevistas foram realizadas com um informante de ocupação em uma escola em Porto Alegre ${ }^{5}$ e em dez grupos de discussão (GD) com até dezessete estudantes durante as ocupações nas escolas. Após a realização dos grupos de discussão foram aplicados questionários semiestruturados a todos (as) presentes nas escolas, totalizando sessenta e cinco estudantes. Dos sessenta e cinco respondentes a variação etária foi dos doze aos vinte anos de idade, sendo mais comum entre dezesseis e dezessete anos (17 e 25 respectivamente). Trinta e seis são mulheres e vinte e nove são homens.

Desse modo, neste trabalho inicialmente serão apresentadas as diferentes perspectivas sobre liderança e formas de construção política a partir do olhar dos estudos realizados em Pelotas e Rio Grande e após será problematizado as diferentes formas de engajamento no processo de formação de liderança junto às ocupações estudantis, bem como as percepções sobre as formas de negociação que foram o desfecho desse processo político.

\footnotetext{
${ }^{3}$ Não identificaremos os (as) estudantes e as escolas no artigo com o intuito de preservar a identidade dos sujeitos da pesquisa por serem na quase totalidade menores de idade e também em razão das ameaças e retaliações que os estudantes passaram durante e após as ocupações.

${ }^{4}$ Esta etapa da pesquisa foi orientada pelo método documentário (BOHNSACK, 2011; WELLER; PFAFF, 2013), questionando-se os grupos sobre os procedimentos da ocupação, mais especificamente sobre como se deu o início da ocupação, como era o cotidiano durante a ocupação e como foi o processo de decisão para o seu término. Faz parte do método o aprofundamento de questionamentos de acordo com as respostas elaboradas pelos(as) respondentes.

${ }^{5}$ A entrevistada foi escolhida por ter participado de ocupação em escola na capital e também por ter participado de organização que acompanhava os debates entre as escolas e os rumos do processo de conflito, além de apresentar informações sobre as disputas que se colocavam à época, assim como a identificação das demais organizações que estavam à frente da negociação com o governo do estado.
} 


\section{As diferentes percepções teóricas sobre a noção de liderança: entre a personificação e o comprometimento}

Tomamos a socialização política como experiência, ressalva necessária, pois é comum, como observou Castro (2009), que essa noção seja tratada muitas vezes como mera transmissão, ou como tábula rasa os (as) jovens diante dos saberes requeridos à sociedade. Para tanto, buscamos nos processos de socialização política, pretéritos e presentes, quais elementos são significativos para perceber a ocorrência e a rejeição da diferenciação entre líderes e liderados para construção dos processos de ocupação, o que ocorre no processo de socialização política desta experiência específica, como novidade para um grupo significativo de participantes e também considerando experiências pretéritas, em especial entre aqueles que já tem histórico de participação política.

A compreensão do conceito de liderança que pode estar bastante vinculado a uma forma relacional, como afirma Outhwite et al., a "[...] qualidade que permite a uma pessoa comandar outras. Isso implica que a liderança é, acima de tudo, uma relação mútua entre líder e liderado, indivíduo e grupo. [...] Por fim, liderança é evidentemente uma relação baseada em aquiescência, não em coerção [...]" (1996, p. 426).

Uma abordagem possível é a compreensão de que o surgimento de lideranças é inerente às organizações, as quais se transformam em oligarquia com o passar do tempo e substituem a vontade dos representados pela sua (MICHELS, 1982). De qualquer modo, tal interpretação sugere que o surgimento das lideranças é imanente à constituição de organização e das dinâmicas políticas nas quais se envolvem.

Entretanto, Bourdieu (2004) desenvolveu este entendimento através da análise do monopólio de capital político por parte de um grupo dentro das organizações, o qual é oriundo pela disponibilidade seja de tempo, dinheiro, ou ambos, para que os envolvidos possam tornar-se conhecedores e aplicadores de maneiras específicas de agir, falar, ter acesso a recursos entre outros elementos que constituem o campo político, e que assim acabam por restringir o acesso ao público em geral da possibilidade de se tornarem agentes políticos.

Sob essa perspectiva, os (as) estudantes em Pelotas e Rio Grande nas ocupações tiveram a sua organização inicial geralmente pelas redes sociais, com a realização de assembleias ou pelo menos de uma reunião com os (as) demais estudantes da escola, ora contando com apoio de alguns professores, alguns pais/mães/responsáveis e a com resistência de outros (as). Perguntamos sobre o grau de participação nas ocupações. Sete responderam ter participação eventual, indo poucas vezes à ocupação durante a semana. Dez disseram que 
acompanham frequentemente, indo todos os dias, mas ficando algumas horas. Quarenta e sete disseram participar intensivamente, permanecendo durante todo o dia e na maioria dos casos ficando também à noite.

Sobre participação prévia em atividades políticas, quatorze respondentes já haviam participado de alguma forma de manifestação, sendo citados construção de grêmio estudantil, coletivos partidários juvenis e manifestações públicas em apoio aos professores em greve. Para cinquenta e um dos respondentes a ocupação é a primeira forma de participação política. Em relação a esses dados, o estudante da Escola $\mathrm{F}$ fez o seguinte relato:

\begin{abstract}
Ah no começo eu e uma colega a gente só queria fazer um pequeno movimento, só queria fechar o colégio rapidão, só pra dar um apoio pros professores, só isso, mas a gente foi conversando, foi conversando, aí eu fiz um grupo no facebook, só que 2 colega meu não quis participar, ficou só eu e minha colega, aí "a gente não vai parar a gente vai fazer alguma coisa pra ajudar", então a gente foi, eu fiz uma assembleia, encontrei outros ocupantes de Pelotas do (escola), no outro dia eles vieram pra cá, daí explicaram tudo, o que a gente precisava fazer pra ocupar, mas foi tudo devagar, foi muito devagar, porque a gente não podia expandir assim, senão não iam deixar, os alunos não iam querer, então a gente foi devagar e a gente ocupou, foi com a ajuda do estudantes da ocupação Escola F.
\end{abstract}

Além de tempo e dinheiro e, especialmente na militância em movimentos sociais, a principal forma de tornar-se portador de capital político se dá pela aquisição de capital militante, o qual é: [...] incorporado sob a forma de técnicas, de disposições a agir, intervir, ou simplesmente obedecer, ele abrange um conjunto de saberes e de savoir-faire mobilizáveis no momento das ações coletivas... (MATONTI; POUPEAU, 2006, p.130). Quando questionados sobre as razões pelas quais decidiram participar da ocupação, quarenta e cinco apresentaram razões políticas, tais como solidariedade aos professores, falta de repasse de verbas às escolas, a proposta estadual da escola sem partido, entre outras. Onze disseram que participaram para acompanhar seus amigos e quatro decidiram participar após acompanhar manifestações dos (as) professores (as). Cinco declararam outras razões, como por exemplo fazer amigos ou não ficar em casa.

A socialização não é nem só nem essencialmente transmissão de valores, normas e regras, mas sim faz parte de um processo de construção de representação de mundo que são produzidas no processo de socialização. Buscamos nas experiências de socialização quais elementos são pertinentes para a formação ou para o interesse na participação política, considerando "influências presentes ou passadas dos múltiplos agentes de socialização e que 
geram uma identidade pelo sentimento de pertencimento a um grupo de referência" (DUBAR, 2005, p. 23-24).

Consideramos o papel do que se compreende como agentes de socialização política, a saber: a família, a escola, os pares e a mídia (OWEN, 2008, p.15). Compreendemos ser fundamental tratar a socialização como não restrita ao contexto de agentes diretos de socialização, mas também o contexto social mais amplo, considerando, necessariamente que a conjuntura política em que os jovens vivem influencia significativamente também para a formação da visão política (PERCHERON; DUPOIRIER, 1975, p. 871-872; BAQUERO; MORAIS, 2016, p.994).

Em relação à socialização política no âmbito familiar, um dos aspectos mais significativos em nossa pesquisa é o baixo índice de familiares que têm alguma forma de envolvimento com o ativismo. Apenas nove estudantes declararam ter familiares envolvidos com ativismo. Não há relação mecânica entre engajamento com base no histórico familiar. Dessa forma, percebemos uma ressignificação da relação entre os pais/mães/responsáveis e os (as) estudantes na discussão ou pelo menos no questionamento sobre a escola e as possibilidades de aprendizagem. Além disso, a partir de uma relação mesmo que conflitiva com os pais/mães/responsáveis, abre-se uma possibilidade de interlocução sobre a decisão das atividades no espaço escolar, conforme se percebe no depoimento abaixo do estudante D na Escola L:

\begin{abstract}
A: E com a atividade que a gente fazia com as crianças de tarde a gente convidava os pais, aí eles viram que a gente não tava aqui só pra bagunça, a gente tava aqui pra tentar mudar, e aí os pais começaram apoiar mais a gente, falar que se a gente precisasse de ajuda podia pedir pra eles.

D: É que no início muitos pais criticaram a gente, falaram um monte de desaforo, mas depois eles viram e nos apoiavam teve até uma mãe que chegou na gente e pediu desculpa É que no começo teve boatos que aqui tava rolando droga, bebida essas coisa e aí eles não tavam levando fé, a aí eles foram vendo que a gente tava fazendo oficina, tava tentando fazer eles nos apoiar, aí uma mãe foi falando pra outra e aí vinha mais gente nos apoiar, foi aumentando.
\end{abstract}

No entanto, também percebemos que aqueles(as) jovens que têm experiências pretéritas de familiares com alguma forma de participação política têm maior "naturalidade" com o processo político em razão da vivência com um habitus militante. A familiaridade com o tema político não leva tendencialmente ao engajamento, requerendo considerar variáveis que constituem a identidade social, e chamamos a atenção para a inter-relação de elementos conjunturais e cotidianos em meio a vida desses estudantes. 
Na socialização política à transmissão e à aquisição de valores, condutas, percepções e preferências sobre a política, embora esse processo possa variar enormemente: em um plano micro, segundo a origem social, a trajetória familiar, nível de instrução, ocupação ou profissão dos indivíduos; e em um plano macro, em função de determinadas conjunturas econômicas, sociais e políticas [...] (TOMIZAKI; CARVALHO SILVA; SILVA, 2016, p. 938).

Compreendemos que a socialização política dos (as) estudantes se deu em um processo de interação em rede com outros grupos e entre estudantes de diversas escolas e cidades que deram sustentação às mobilizações. Durante as ocupações nas escolas pesquisadas em Pelotas e Rio Grande analisamos que alguns aspectos relativos ao questionamento da estrutura escolar, as relações interpessoais e pedagógicas entre a comunidade escolar vieram à tona de diversas formas, seja no diálogo, na compreensão do outro, na questão da participação dos (as) estudantes nas decisões da organização interna da escola pelo grêmio estudantil ou mesmo no diálogo com estudantes de outras escolas. Por exemplo, na Escola G os (as) estudantes a partir do diálogo sem o intermédio da direção ou por estruturas como Associação de Pais ou de estruturas mais tradicionais (Círculo de Pais e Mestres - CPM's) conseguiram explicar suas reivindicações e agregar apoiadores (as) para a ocupação da Escola, como pode ser visto na fala da estudante A:

Bom, pros pais a gente também fez assembleia explicando as Pls pros pais, falando sobre casos que futuramente poderiam acontecer sobre o que que o governo ah.. é... a mídia mesmo pode colocar medo nos pais né, de polícia invadir e tudo mais de bater, ai a gente explicou tudo isso, explicou a importância e explicou as pautas e tudo mais eles ficaram mais tranquilos em relação a isso. Fora que eles apareciam aqui, muitos ajudavam com alimentos e tudo mais dai eles ficaram tranquilos em relação a isso. Até porque como eles tinham o apoio da vice direção.

Os contextos políticos, considerando os exemplos de outras escolas que realizaram ocupações no Chile e em São Paulo, são situações declaradas pelos (as) entrevistados(as) e atualizam a percepção de possibilidades abertas a estes jovens, os quais têm em seus pares e no contexto escolar a conexão necessária para reivindicarem a identidade política necessária ao ativismo. Tem-se especialmente a escola como principal locus de socialização política, pois nela é possível a construção do pensamento de que as experiências de cada jovem constituem elemento de referência comum.

Considerando a questão da família, escola e contexto sociopolítico para a formação de um ethos ativista, percebemos o processo de ocupação da escola como elemento importante 
para a possível formação tanto deste ethos quanto para a definição e surgimento de lideranças, seja pela socialização pretérita ou pela experiência na ocupação. Ainda sobre esse aspecto levamos em consideração que a forma de ocupação diferencia-se significativamente de outras manifestações por constituir-se como espaço continuado de manifestação no qual são geradas formas de interação social mais intensas entre seus participantes por maior período de tempo.

A forma da manifestação ocupação, em razão de sua própria execução gerar um forte sentimento comunal entre seus produtores, conta com três características marcantes: formação de redes pelo convívio prolongado; consolidação de estruturas com normas próprias, baseadas em estratégias definidas pelo grupo para enfrentar situações diversas e, finalmente, a percepção de que seus realizadores têm agência, pelo menos no que diz respeito ao espaço da ocupação, em razão da capacidade de determinar as formas de atuação (PALACIOSVALLADARES, 2016, p.153).

Assim, o comprometimento pode surgir do envolvimento com o grupo e, portanto, se configura como algo que é considerado pelos sujeitos da pesquisa como algo "natural" em razão desta convivência; quando surgem na forma de uma "aposta", não se dão de acordo com um modelo de racionalidade exterior e único, mas de acordo com os valores do grupo de referência, consolidados no processo de ocupação.

Além dos aspectos conjunturais mais amplos, no que tange o processo formação e socialização política dos (as) estudantes na construção das suas reivindicações nas escolas de Pelotas e Rio Grande pesquisadas, mesmo que de forma preliminar, percebemos a referência que eles (as) tinham nas ocupações em SP e depois passaram a ter pelas ocupações no RS e nas suas próprias cidades, a utilização das redes sociais de internet como meio auxiliar de organização e mobilização e uma rede de apoio entre estudantes e apoiadores.

\section{Formas de engajamento para compreensão das diferentes perspectivas liderança}

Percebemos nos relatos dos grupos que uma das motivações iniciais para a realização das ocupações foi a solidariedade com os professores, com salário sem reajustes e parcelado desde o início de 2015. Somado a isto, a insuficiência de recursos nas escolas para alimentação, manutenção do espaço físico e outras pautas que surgiram após o início do debate entre os(as) jovens e, posteriormente, no contato entre as diversas escolas, fez surgir a construção do ciclo de confrontos em razão da percepção de que estavam construindo uma pauta comum. 
O processo de debate para construção das ocupações ocorreu nas escolas, via de regra, em organização por assembleias convocadas inicialmente por um grupo mais restrito de estudantes que previamente já discutiam as carências estruturais acima mencionadas. A partir daí questionamos:

\section{Há alguma característica comum entre os(as) jovens indicados(as) como lideranças?}

Ao longo do processo de pesquisa, no cruzamento de variáveis que poderiam indicar a compreensão de liderança, há uma forte correlação nas escolas pesquisadas com a participação em outras organizações, seja grêmio estudantil, coletivos ou atividades com os demais ocupantes, sendo, portanto relevante à densidade das relações sociais. Não se trata tal densidade para a totalidade dos respondentes, necessariamente, um ativismo prévio, mas o ingresso em outros espaços de socialização política e que são frequentados também pelas pessoas indicadas como lideranças no processo de ocupação.

Um dos questionamentos foi sobre o envolvimento dos familiares em política, seja partidária, sindical ou outra. Essa variável aparece como uma das razões da constituição de um habitus militante e serviu para esta pesquisa tanto para verificação da incidência de casos como para análise da hipótese de que são estes(as) jovens, em razão de um eventual capital militante, advindo da socialização primária, que ocupariam o papel de liderança.

Como abordamos anteriormente, dos sessenta e cinco respondentes, apenas nove declararam que algum familiar era envolvido com política. Os tipos de participação descritos foram o ativismo virtual, movimento negro, feminismo, sindical, partidário e participação de irmão na ocupação. Destes, seis já participaram previamente à ocupação de alguma forma de manifestação política, sendo citadas participação de plenária do Partido Socialismo e Liberdade (PSOL), protestos do Movimento dos Trabalhadores Rurais Sem Terra (MST), Marcha Mundial das Mulheres (MMM) e Kizomba, militância na União Brasileira dos Estudantes Secundaristas (UBES) e manifestações com professores vinculados ao CPERS Sindicato. Destes respondentes, especificamente em relação à variável liderança, dois disseram que todos são líderes e sete declararam haver liderança(s) na ocupação. Apenas dois se autodeclararam enquanto lideranças.

Conforme as características do universo de pesquisa, centrada em uma saturação de recorte qualitativo, não é possível afirmar que a atuação pregressa ou atual dos familiares com política determina o engajamento dos (as) jovens em atividades políticas. No entanto, percebemos que entre os (as) jovens que os familiares não participavam de política (cinquenta e quatro respondentes), oito disseram que tiveram alguma forma de participação em atos ou manifestações previamente à ocupação, ao passo que entre os que têm familiares que 
participaram ou participam de alguma forma de política (nove respondentes), seis disseram que previamente se envolveram ou participaram de protestos. Assim, respectivamente, $15 \%$ com histórico de envolvimento cujos pais não têm envolvimento com ativismo e $66 \%$ com histórico prévio de engajamento cujos familiares têm envolvimento com ativismo político. Nesta pesquisa a escolaridade destes familiares não é significativa para determinar tal envolvimento, apresentando desde fundamental incompleto a superior completo.

A existência prévia na família de sujeitos atuantes na política torna "natural" a sua prática posterior, não levando, necessariamente, ao seu exercício. Percebemos isto ao ler o relato de uma jovem que realizou a ocupação em Porto Alegre:

É porque assim, a minha família é muito envolvida com política. Muito. Então eu cresci nesse meio assim. Minha mãe é pedagoga, meu pai é consultor em dependência química. [...] E os meus tios são muito envolvidos com política. Muito, muito, muito, muito. Eu cresci indo em bandeiraço do PT. Então a gente sempre teve essa base política muito forte dentro da minha casa assim. Muito. E daí quando meus pais me colocaram dentro dessa escola foi fomentado mais ainda, porque essa escola tem, ela tinha um cunho muito político assim. Muito mesmo assim, de professores que se colocavam, falavam sabe? Colocavam presente na sala de aula, que davam versões diferentes que a gente não conhecia e que fomentavam o debate dentro da sala de aula. Então essa formação veio desde sei lá... (Informante, 2017).

Consideramos esse fator como pertinente mas não central, pois esteve presente contudo não se demonstrou como regra em todas as situações observadas. O exercício de uma liderança reconhecida entre os(as) estudantes que participaram da pesquisa não requer um capital militante adquirido no âmbito familiar. Nas entrevistas aparecem apontados pelos demais mais quando estes percebem uma "entrega" à ocupação, no sentido de envolverem-se na organização, tarefas e nível de comprometimento e presença cotidiana. Abaixo, transcrevem-se três respostas da escola $\mathrm{G}$ em que os(as) entrevistados(as) foram unânimes na identificação de liderança: "Sim, houve liderança de duas pessoas por terem um conhecimento maior do que os demais." "Sim o [fulano] e eu, porque eram os mais engajados e quem passavam mais tempo lá dentro." "[...]os que tinham mais experiência em movimentos e protestos."

Um dos estudantes indicados pelos demais como liderança no questionário compreende-se enquanto referência e apresenta tal papel com base em sua militância, como segue: "Sim. Acredito que fui um bom militante na ocupação."

Já nos casos de negação da existência de lideranças, os respondentes afirmam que não há liderança e todos são líderes. A principal justificativa é de um comprometimento 
generalizado, além da compreensão de que o processo organizativo e decisório é realizado de maneira coletiva, na busca de agregar o conjunto no processo decisório, conforme relato:

A gente fez duas assembleias com os estudantes. Convocamos eles falando que a gente faria uma assembleia e que a pauta seria ocupação. E chegando lá os estudantes foram e tal, e teve um baita de um debate, não sei o que, e a gente apresentou aquilo que as nossas pautas e como que a gente via toda aquela situação. Só que sempre a gente colocou que aquilo não era um movimento só do grêmio estudantil, porque o grêmio estudantil tomou a iniciativa, mas quando o grêmio estudantil tomou a iniciativa outros estudantes se juntaram àquilo. A gente sempre quis deixar claro que aquele movimento não era um movimento do grêmio estudantil, mas sim de vários estudantes porque não tinha só o grêmio estudantil lá dentro (Informante, 2017).

Há, portanto, diferentes percepções sobre as formas de engajamento do grupo: quando se percebe nível de engajamento diferenciado há tendência de identificação de lideranças e, ao mesmo tempo, a visão de comprometimento e participação homogênea tende a rejeitar a noção de liderança, vista de modo geral em especial como representação, desde que seja oriunda da participação na ocupação e deliberada coletivamente, como expresso em grupo de discussão:

A única coisa que deu bronca foi pelas lideranças, porque todo mundo queria chegar ali na frente e falar, mas tinha pessoa que não sabia nem o que tava fazendo aqui e queria falar lá, aí a gente que organiza, só duas pessoas ir falar lá, teve muita coisa que as pessoas chegavam ali na frente e não sabia o que falar, falava qualquer coisa (Grupo de discussão na Escola A, 2016).

A noção de liderança também apareceu de maneira considerada "negativa" na forma de não reconhecimento da União Brasileira de Estudantes Secundaristas (UBES) e alguns partidos que compuseram a mesa de negociação dos pontos exigidos pelas escolas e no processo de desocupação. As duas principais contestações de muitos grupos ocorreram pelos relatos de falta de diálogo sobre a construção das pautas e também de que muitos dos que estavam à frente "não representavam" os (as) estudantes, especialmente por não participarem do cotidiano das ocupações, gerando um "racha" no processo de deliberação sobre ações a executar. Devido a isso os(as) estudantes formaram uma organização autônoma que não reconhecia UBES e a legitimidade de algumas organizações, em especial o Partido Pátria Livre (PPL) que, segundo relato, "mandava" na União Metropolitana dos Estudantes Secundários de Porto Alegre (UMESPA), na União da Juventude Socialista (UJS) e no Movimento Esquerda Socialista (MES), conforme segue em relato: 
O CEI é o comitê das escolas independentes. O que acontece? Com as reuniões das escolas de todas as escolas né que tinha, tanto as que tavam ocupadas pela UBES, UJS, MES, tanto as que estavam ocupadas por essas organizações quanto as que não estavam ocupadas por essas organizações, a gente fazia assembleias, né. Pra decidir, pra deliberar o rumo do movimento. [...] Assembleias gerais bem conturbadas. [...] E dentro dessas assembleias iam essas organizações e não sei o quê. Iam um monte de universitários e dentro, se a gente pegasse todas pessoas que iam nas assembleias, menos da metade eram secundaristas que tavam ocupando as escolas, sabe? Que conheciam, que viviam aquilo. E o resto era universitário que tava querendo opinar no movimento, era organização que tava querendo opinar no movimento. E tava querendo puxar a corda pro seu assado, entendeu? Não era uma coisa, ai, como sou bonzinho com vocês. Tinha um objetivo. Qualquer posicionamento, qualquer fala que eles tinham, tinha um posicionamento. Tinha um porquê deles falarem aquilo. Então a gente percebeu que eles tavam roubando a nossa voz. Roubando nosso protagonismo como estudante. E aí o CEI fez um racha. Se juntou às escolas que não estavam de acordo com aquilo, que não tavam de acordo com o rumo que tavam tomando as assembleias gerais, que não tava de acordo com a presença de universitário opinando pelo movimento (Informante, 2017).

O estranhamento também ocorreu em alguns grupos estudantis do interior do estado, principalmente pela compreensão de que não estavam sendo incluídos no processo decisório, mas apenas na escolha de representação, sem que isto significasse participação de fato nas negociações e decisões sobre a coletividade das escolas ocupadas no estado, conforme relato abaixo:

E aí chegou um dia em Porto Alegre, eu tenho que falar isso bem ressaltado, chegou em Porto Alegre e a gente recebeu uma notícia que a UBES pegou e assinou um acordo que a gente fecharia as ocupações até um certo dia, senão o colégio ia pagar 10 mil reais por dia que permitisse que a gente ficasse lá, e foi muito ridículo porque quem é a UBES? Tipo, até eu perguntei pra um cara da UBES, porque assinaram ai falaram: 'ah porque é um movimento que acerta em greves, que retrocedeu não sei o quê' só que a votação não foi unânime, tá ligado? Eles dizem que eles... que eles pegam e chamam alunos pra votar no presidente da UBES, que agora é uma presidente só que eu nunca vi, ninguém nunca viu, eles pegam um aluno de cada escola, tipo eles vem aqui pegam um aluno [escola $\mathrm{A}$ ] e levam pra lá pra votar, os cara levam os cara pra votar neles porque se eu vou viajar com alguém, tipo o cara tá me levando pra viajar, eu vou votar nele, não conheço mais ninguém entendeu? Tipo na minha cabeça, na minha opinião eu acho que isso é tipo muito ridículo, é tipo fazer... é fazer a cabeça dos alunos, a gente... eu não votei neles, a maioria da minha escola não votou neles, entendeu? (Grupo de discussão Escola M, 2016).

Percebemos a diferença na percepção sobre a liderança de acordo com a noção de comprometimento com base na participação e inclusão do conjunto no processo decisório. Se percebe que há uma ou duas pessoas que realizam mais tarefas, se envolvem mais, têm mais "conhecimento", significando o entendimento de que quem é a rede social que articula a 
ocupação, e, em síntese, organiza o conjunto de atividades, ou como dizem, "toma a frente", é visto como liderança, não eximindo da responsabilidade sobre o compartilhamento de como se deu o processo decisório.

Por outro lado, entre os(as) respondentes que tomam para si essas tarefas, mesmo que dividindo tarefas, mas se compreendem como igualmente comprometidos, a designação de liderança desaparece. Nestes casos, o protagonismo da realização das atividades que são compreendidas como indispensáveis para manutenção da ocupação por parte de um grupo, continua a existir sem, no entanto, a identificação formal deste papel.

Consideramos ainda que a interpretação do movimento a respeito do governo estadual, no caso conhecido como "governo Sartori" e, em alguns casos, da direção da escola, que encarnam os antagonistas a quem se dirigem as pautas, variava conforme a conjuntura. Durante as ocupações das escolas, mesmo em meio a processos dialógicos e conflitivos, a ação dos (as) estudantes tinham uma dimensão estratégica na construção das pautas, na autoorganização e na construção de ações autônomas diante de outras categorias.

Assim, observamos que um dos possíveis determinantes da consolidação de liderança ou não nas ocupações também é o desenvolvimento da noção de comprometimento, dito conforme Becker como (1960):

[...] os compromissos não são necessariamente feitos conscientemente $\mathrm{e}$ deliberadamente. Alguns compromissos resultam de decisões conscientes, mas outros surgem progressivamente. O sujeito se torna consciente de que está comprometido apenas em algum momento de mudança e parece estar comprometido sem perceber (Becker, 1960, p. 38. tradução nossa).

São tais valores e a sua defesa que em certos casos, como esse, que constituem o que seria reconhecido como comprometimento. Estes apresentam-se, via de regra, pela expressão de determinado diagnóstico e prognóstico político do momento, e em especial pela noção da importância do coletivo.

\section{Considerações finais}

Um dos aspectos comuns ao conjunto das mobilizações é relativo às medidas adotadas pelos governos com um expediente "neoliberal" com a falta de investimento com a subsequente terceirização e até privatização dos serviços públicos com o discurso de que os estados devem cortar seus gastos com políticas sociais. Com as ocupações secundaristas de 2016, no Rio Grande do Sul e nos demais estados brasileiros, viu-se a incorporação destas 
tensões entre a ocupação dos espaços, a reivindicação de direitos públicos, ou seja, essas reivindicações se inserem em uma conjuntura mais ampla do ensino público brasileiro e explicitam tendências em curso em todo o país e em diversos países, como, por exemplo, na América Latina.

Além dos aspectos conjunturais mais amplos, no que tange o processo formação e socialização política dos (as) estudantes na construção das suas reivindicações nas escolas ocupadas, mesmo que de forma preliminar, percebemos que o processo político de construção das ocupações possibilitou o questionamento e a reelaboração de um saber prático e político em relação às formas consolidadas ou consideradas tradicionais de representação ou liderança política.

Ocorreram casos de personificação em um ou mais sujeitos (as) do papel de mobilização, que auxilia na continuidade da ocupação, ao passo que a construção de "todos são liderança" também serve como alternativa para mobilização desses (as) estudantes. Compreende-se que há em um caso a junção de representação e mobilização, sendo substituída no segundo caso pela autorrepresentação. Cabe a noção de constituição de capital militante (Matonti e Poupeau, 2006) ser, no primeiro caso, escasso e, assim, gerar capital político, expresso em representação que é legitimada quando informa ao grupo os processos práticos. Em outra situação, o capital militante é difundido no grupo e a representação torna-se desnecessária em pequena escala pois, nestes casos, grande parte dos (as) estudantes realizam as tarefas e fazem parte diretamente dos processos decisórios e práticos cotidianos.

Percebemos que ainda é significativa a distinção entre interior do Estado e capital como forma de relacionar distância, não somente geográfica, mas representativa do centro de decisões sobre os rumos da ocupação, os quais foram, ao final, deliberados pela União Brasileira de Estudantes Secundaristas (UBES). Tal entidade negociou com o governo do RS o final das ocupações e, ao não incluir muitos (as) estudantes no processo decisório, foi compreendida por estes como liderança ilegítima, empregando os valores que adotaram para decidir quem são, de fato, os (as) estudantes que realizaram as ocupações.

Sob essa perspectiva e diante do conjunto de aspectos discutidos ressaltamos que seria prematuro dizer que as ocupações estudantis são movimentos de massa e serão um repertório de mobilização estudantil usual como manifestações, greves e passeatas promovidas por sindicatos, associações corporativas, partidos políticos, movimentos sociais etc. Entretanto, cabe considerar que as ocupações das escolas feitas pelos (as) estudantes é uma das formas de protesto que como um fator que tensiona e inova as formas de sociabilidade política 
conhecidas entre atores políticos no século XXI, desde as grandes manifestações de rua em junho de 2013 no Brasil.

\section{REFERÊNCIAS}

BAQUERO, Marcello; Baquero, Rute V. A.; Morais, Jennifer A. de. Socialização Política e internet na construção de uma cultura política juvenil no sul do Brasil. Educação e Sociedade. Campinas, v. 37, nº 137, pp. 989-1008, out-dez. 2016.

BECKER, Howard S. Notes on the concept of Commitment. American Journal of Sociology, vol. 66, $\mathrm{n}^{\mathrm{o}}$ 1, pp. 32-40.1960.

BOURDIEU, Pierre. O poder simbólico. $7^{\mathrm{a}}$ ed. Rio de Janeiro: Bertrand Brasil.2004.

CASTRO, Lucia Rabello de. Juventude e Socialização Política: atualizando o debate. Psicologia: teoria e pesquisa. Brasília, out-dez, v. 25. n. 4, p. 479-487.2009.

CATTANI, Antonio D. (Org.) Escolas ocupadas. Porto Alegre: CirKula, 2017. 160 p.

CATINI, Carolina de Roig; MELLO, Gustavo Moura de. Escolas de luta, educação política. Educação \& Sociedade. Campinas, v. 37, no 137, p. 1177-1202, out-dez., 2016.

CORTI, Ana Paula de Oliveira; CORROCHANO, Maria Carla e SILVA, José Alves da. "Ocupar e Resistir": a insurreição dos estudantes paulistas. Educação \& Sociedade. Campinas, v. 37, $\mathrm{n}^{\mathrm{a}}$ 137, p. 1159-1176, out-dez. 2016.

DUBAR, Claude. A socialização: construção das identidades sociais e profissionais. São Paulo: Martins Fontes.2005.

FONTANELLA, Bruno Jose Barcellos et al . Amostragem em pesquisas qualitativas: proposta de procedimentos para constatar saturação teórica. Cad. Saúde Pública, Rio de Janeiro, v. 27, n. 2, p. 388-394, Feb. 2011.

MATONTI, Frédérique; POUPEAU, Frank. O Capital Militante: uma tentativa de definição. Plural. São Paulo, n. 13, p.127-134. 2006.

MICHELS, Robert. Sociologia dos partidos políticos. Brasília, UNB.1982.

OWEN, Diana. Political socialization in the Twenty-first century: recommendations for researchers. IN: Center for civic education and the Bundeszentrale fur Politische Bildung: the future of civic education in the 21st Century. James Madison’s Montpelier.2008.

PALACIOS-VALADARES, Indira. Protest communities and activist enthusiasm: student occupations in contemporary Argentina, Chile and Uruguay. Interface: a journal for and about social movements. volume 8 (2): pp. 150-170. 2016.

PERCHERON, Annick; DUPOIRIER, Élisabeth. Choix idéologiques, attitudes politiques des pré-adolescents et contexte politique. Revue Française de Science Politique. $25^{\mathrm{e}}$ année, $\mathrm{n}^{\circ} 5$, pp. 870-900. 1975. 
ROSÁRIO, Nísia Martins do; SILVA, Caio Ramos da; SILVA, Sanielle Miranda. Ocupações dos secundaristas do RS: tensões culturais e reconfigurações comunicativas. Intexto. Porto Alegre, UFRGS, n. 37, p. 193-214, set/dez 2016.

SALLAS, Ana Luisa Fayet. E a luta continua! \#OCUPATUDO: Potência e dilemas da ação política. Interseções. Rio de Janeiro, V. 19 nº 2, p. 463-482, dez. 2017.

SILVA, Bárbara Virgínia Groff da; SILVA, Eduardo Cristiano Hass da. "Uma pá de ocupação": ocupações escolares e atuação juvenil no Rio Grande do sul (2016). Teias, Rio de Janeiro, v. 18, n 50, jul/set. 2017.

WELLER, Wivian; PFAFF, Nicolle. Metodologias da pesquisa qualitativa em educação. Petrópolis: Vozes, 2013.

\section{SOBRE OS AUTORES:}

\section{Ricardo Gonçalves Severo}

Doutor em Ciências PUC-RS. Universidade Federal do Rio Grande (FURG). Rio Grande-RS. Área de Sociologia - Instituto de Ciências Humana e da Informação (ICHI). Docente do Programa de Pós-Graduação em Educação (PPGEDU) - FURG E-mail: rg.severo@hotmail.com. Integra o Grupo de Pesquisa em Dinâmicas Políticas, Estado e Movimentos Sociais (DIPEM) - FURG e Integrante do Grupo de Pesquisa Gerações e Juventude (GERAJU) - UnB.

iD http://orcid.org/0000-0001-8413-7159

\section{Sérgio Botton Barcellos}

Doutor em Ciências Sociais CPDA- UFRRJ. Universidade Federal do Rio Grande (FURG). Rio Grande - RS. Área de Sociologia - Instituto de Ciências Humana e da Informação (ICHI). Docente do Programa de Pós-Graduação em Educação Ambiental (PPGEA) - FURG e do Programa de Pós-Graduação em Sociologia - UFPel. E-mail: sergiobbarcellos@ hotmail.com .Coordenador do Grupo de Pesquisa em Dinâmicas Políticas, Estado e Movimentos Sociais (DIPEM) - FURG.

(iD http://orcid.org/0000-0002-6395-4398

\section{Mário Augusto Correia San Segundo}

Mestre em História pela UFRGS. Doutorando em Educação UFRGS. Instituto de Educação, Ciência e Tecnologia do RS (IFRS). Viamão - RS. Professor de História. E-mail: contramola@gmail.com . Integra o Grupo de Pesquisa em Dinâmicas Políticas, Estado e Movimentos Sociais (DIPEM) - FURG.

http://orcid.org/0000-0002-4199-000X 